\title{
On the mechanism of the organocatalyzed Beckmann rearrangement of cyclohexanone oxime by trifluoroacetic acid in aprotic solvent
}

\author{
L. Ronchin*, A. Vavasori \\ Chemistry Department, Università Ca' Foscari Venezia, Dorsoduro 2137, 30123 Venice, Italy
}

\section{A R T I C L E I N F O}

\section{Article history:}

Received 16 April 2009

Received in revised form 16 July 2009

Accepted 17 July 2009

Available online 24 July 2009

\section{Keywords:}

Beckmann rearrangement

$\varepsilon$-Caprolactam

Trifluoroacetic acid

Mechanism

Reaction rate

\begin{abstract}
A B S T R A C T
The Beckmann rearrangement of cyclohexanone oxime to $\varepsilon$-caprolactam in high yield catalyzed by trifluoroacetic acid in aprotic solvents is described. The influence of the concentration of reagents, intermediates, solvents on reaction rate and selectivity in $\varepsilon$-caprolactam is studied. The identification of the key intermediate and its role in the catalysis are reported together with the influence of the acid on the reaction rate. In addition, the study of the hydrolysis reactions of reagent and intermediates highlights what are the parameters that influence the selectivity to $\varepsilon$-caprolactam. On the basis of these results a likely catalytic cycle based only on the experimentally verified intermediates is also given.
\end{abstract}

(C) 2009 Elsevier B.V. All rights reserved.

\section{Introduction}

Despite the environmental and the industrial concerns relating the production of $\varepsilon$-caprolactam [1-4] by Beckmann rearrangement of cyclohexanone oxime employing oleum as homogeneous catalyst, the new heterogeneous gas phase processes are far from being widely employed in the industrial production [3-6]. The reasons are both economical and technical and deeply related between them, indeed the fast catalyst deactivation needs of complex plant design for a continuum catalyst regeneration, which limits their practical application [6].

Recently, progresses on the homogeneous Beckmann rearrangement are observed by using organocatalysis [7,8]. Even though, these studies derive directly from the ones of Beckmann and Kuhara $[9,10]$, and involved many researchers during the XX century, the argument is yet greatly studied due to its important practical application in the revamping of traditional processes [3,4]. The use of strong inorganic acids in the Beckmann rearrangement of cyclohexanone oxime is a common synthetic practice [11-14] and a more environmentally friendly approach may be attempted. For instance, recently the use of ionic liquids in combination with lewis acids give high yield and selectivity with some activated oxime but not really significantly in the rearrangement of the cyclohexanone oxime for this reasons a practical development of a process based on these catalytic systems seems to be, at the moment, impracticable

\footnotetext{
* Corresponding author.

E-mail address: ronchin@unive.it (L. Ronchin).
}

$[15,16]$. On the contrary, use of quite mild acid with low protonation ability such methanesulfonic, sulfamic and more recently trifluoroacetic acid in non-aqueous solvent, showed high yield in $\varepsilon$-caprolactam and could be a useful approach to an ammonium sulfate-less process $[7,8,17,18]$. In the acid catalyzed Beckmann rearrangement the key points are the proton transfer from the nitrogen to the oxygen and the concerted extraction of the water molecule with the displacement of the carbon atom. This process is allowed by the formation of electron-poor nitrogen, which is the driving force for the rearrangement. According to this, the conversion of the oximes to more reactive ether or ester intermediates is a practical method to achieve the rearrangement under mild conditions [19-24]. As a matter of fact, these compounds, respect to the corresponding oximes, have a lower electronic density on the nitrogen atom and consequently a greater tendency to rearrange even without Brønsted acids [19-24]. For this reason a new catalytic pathway based on the rearrangement of acetyl cyclohexanone oxime, under mild acidic condition, to acetyl caprolactam was studied [17]. On the progress of these studies, bring us to study the reactivity of trifluoroacetyl cyclohexanone oxime and the reactivity of the neat oxime in the presence of trifluoroacetic acid as a catalyst: $\varepsilon$-caprolactam in high yield was obtained in non-aqueous solvent [18].

In the present paper we give new insight on the Beckmann rearrangement of cyclohexanone oxime catalyzed by $\mathrm{CF}_{3} \mathrm{COOH}$ in aprotic solvent, a detailed study of the stages of the process and some data relative to the rate of reaction of the single step are studied, in order to discriminate what are the determining steps for the kinetics. 


\section{Experimental}

\subsection{Materials}

Reagents: cyclohexanone oxime, $\varepsilon$-caprolactam, trifluoroacetic acid, trifluoroacetic anhydride, were purchased from Aldrich. The purity of the commercially available samples was checked by the usual methods (melting point, TLC, HPLC, GC and GC-MS) and further purifications were carried out when necessary. In particular, cyclohexanone oxime was crystallized from cyclohexane, dried in vacuo and stored under nitrogen at $248 \mathrm{~K}$. Reaction solvents were HPLC grade products used without further purifications. Deuterated acetonitrile was purchased from Euriso-Top.

\subsection{Trifluoroacetyl cyclohexanone oxime and N-trifluoroacetyl caprolactam synthesis}

The synthesis of trifluoroacetyl cyclohexanone oxime was carried out by drop wise addition of trifluoroacetic anhydride to a diethyl ether solution of cyclohexanone oxime at $273 \mathrm{~K}$. Checked the conversion by CG analysis (completeness after few minutes) the reaction mixture is washed with a solution of $\mathrm{NaHCO}_{3}$ at $273 \mathrm{~K}$ and desiccated with anhydrous $\mathrm{Na}_{2} \mathrm{SO}_{4}$. Finally distilled under vacuum with a final GC purity of $\mathrm{ca}$. $96 \%$.

The synthesis of N-trifluoroacetyl caprolactam is similar to that of the trifluoroacetyl cyclohexanone oxime except for the temperature of reaction, which is $298 \mathrm{~K}$. In addition, the solution is not washed with aqueous $\mathrm{NaHCO}_{3}$ because of the strong tendency of $\mathrm{N}$-trifluoroacetyl caprolactam to hydrolyze and the solution is distilled under vacuum without any treatment. Both trifluoroacetyl cyclohexanone oxime and N-trifluoroacetyl caprolactam are characterized by GC-MS and NMR measurements and their purity (ca. $96 \%$ ) are checked by GC analysis.

\subsection{Reaction rates measurements}

The kinetic runs were performed in a well stirred pressurized glass reactor thermostatted by a circulation bath in the range 354-383 K and containing weighed samples of the solvent and of the reagents. Small amounts $(c a .10 \mu \mathrm{l})$ of the reaction mixtures were drawn at different times and the samples were analyzed by GC and GC-MS, using an HP5 capillary column (300 $\mu \mathrm{m}$ i.d. $30 \mathrm{~m}$ long, 95\% methyl, 5\% phenyl silicone phase). The samples were also checked by HPLC using a PerkinElmer apparatus and a Lichrosphere 100 (RP-18, $5 \mu \mathrm{m}$ ) column with water acetonitrile 30/70 as eluent.

\section{Results and discussion}

The results reported below comprise some data already reported in preliminary works which have been included for a better comprehension of the argument.

\subsection{Time concentration profiles and reaction steps}

In Fig. 1 the typical time concentration profile in acetonitrile $(\mathrm{ACN})$ as a solvent is reported. The formation of cyclohexanone, which is the major side reaction, will be extensively discussed in next section. Both trifluoroacetyl cyclohexanone oxime and $\mathrm{N}$ trifluoroacetyl caprolactam are observed in small amount from the beginning of the reaction, thus suggesting their active involvement into the reaction mechanism.

The likely reaction steps inferred from the time concentration profile are reported in Scheme 1, as already discussed in previous work the esterification of the cyclohexanone oxime and its further rearrangement to the corresponding trifluoroacetyl caprolactam are key steps of the reaction. In fact, the rearrangement via

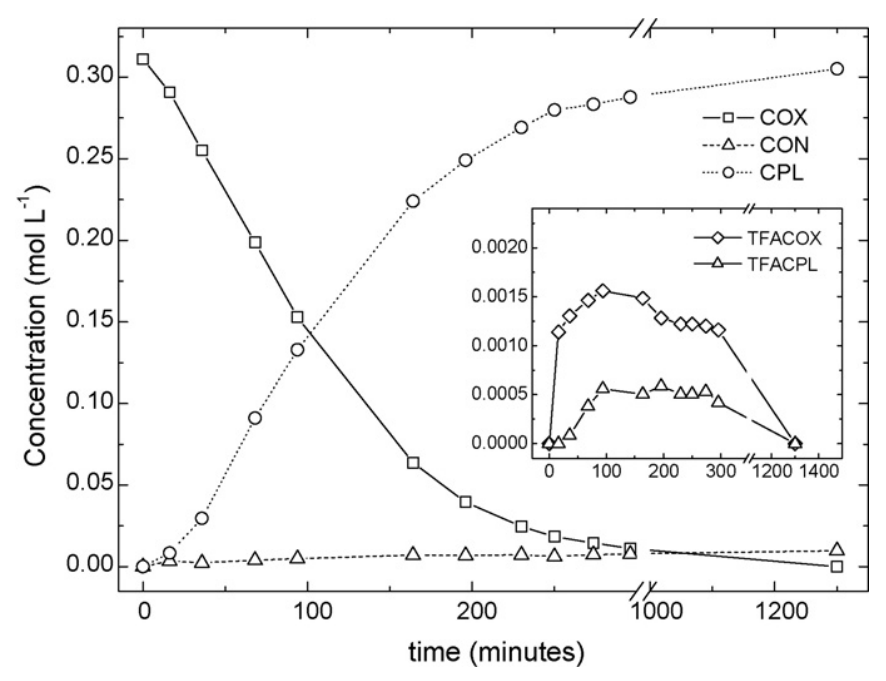

Fig. 1. Typical time concentration profiles in $\mathrm{ACN}$ as a solvent. Run conditions: $T 363 \mathrm{~K}$, cyclohexanone oxime concentration $0.31 \mathrm{~mol} \mathrm{~L}^{-1}, \mathrm{CF}_{3} \mathrm{COOH}$ concentration $1.0 \mathrm{~mol} \mathrm{~L}^{-1}$, reaction volume $10 \mathrm{~mL}$. COX=cyclohexanone oxime, $\mathrm{CPL}=\varepsilon$-caprolactam, $\mathrm{CON}=$ cyclohexanone, $\mathrm{TFACOX}=$ trifluoroacetyl cyclohexanone oxime TFACPL $=\mathrm{N}$-trifluoroacetyl caprolactam.

trifluoroacetyl cyclohexanone oxime is more facile than the direct rearrangement of the neat oxime due to the loosening of electronic density at the nitrogen induced to the electron withdrawing effect of the trifluoroacetyl group [19,22,23].

\subsection{Influence of the solvent on reaction rate and selectivity}

In Table 1 the influence of several solvents and mixture on initial reaction rate and selectivity is reported. It is noteworthy that the reaction rate, except in dimethylformamide (DMF) and dimethyl sulfoxide (DMSO), moderately increases with the polarity of the solvent, while the selectivity to $\varepsilon$-caprolactam (except in benzonitrile, DMF and DMSO) are negligibly influenced, this behavior suggests a rate determining step whose active complex is poorly stabilized by solvation [25]. Different considerations must be accounted for DMF and DMSO, in which the reaction gives different products. As a matter of fact, in DMF reaction stops after $30 \mathrm{~min}$ with $60 \%$ of conversion of cyclohexanone oxime (Fig. 2), $\varepsilon$-caprolactam concentration reaches a maximum (after $15 \mathrm{~min}$ ) then decreases, probably due to side reactions such as the polymerization of the lactam [26]. In DMSO the rearrangement does not occur at all and only the hydrolysis to cyclohexanone is observed. The results in DMSO are the contrary of what expected because it has been reported that in some cases the rearrangement rate slightly increases with the solvent polarity [18]. The reason of such a behavior is not clear, however, cage formation in which cation or anion are trapped is known to occur in DMSO, so that a specific solvent effect may be conjectured for this solvent [27].

The inhibiting effect of DMSO on the rearrangement is studied in order to highlight not only the solvent effect on the reaction but also the mechanism itself. In Fig. 3 the time concentration profile of the rearrangement in the presence of DMSO is reported, the shape of the profile does not differ significantly of what observed in neat $\mathrm{ACN}$, except for the lower initial reaction rate and for the very low concentration of the trifluoroacetyl derivatives, which are detectable only in trace amount (about $10^{-5} \mathrm{~mol} \mathrm{~L}^{-1}$, for this reason their concentration time profiles has been omitted due to the high uncertainty of the measure). The influence of the concentration of DMSO on both the initial reaction rate and the selectivity to $\varepsilon$-caprolactam is reported in Fig. 4 . As expected, the initial rate diminishes as the concentration of DMSO increases, which confirms 


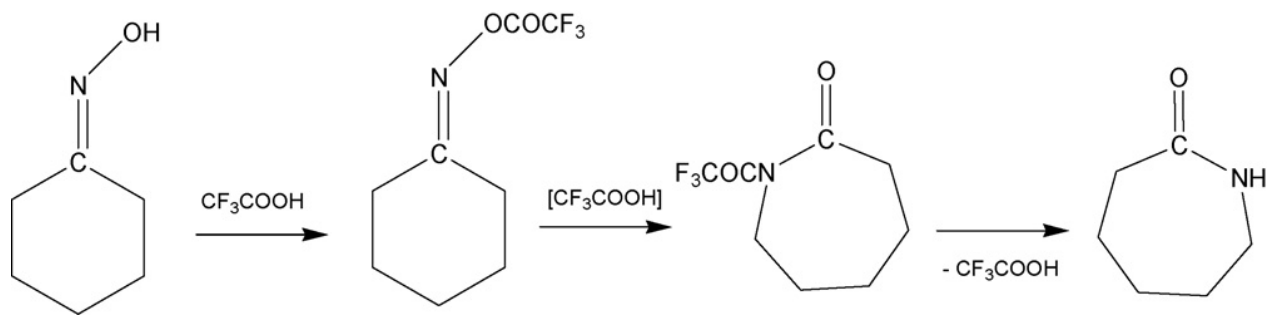

Scheme 1. Reaction steps of the rearrangement catalyzed by $\mathrm{CF}_{3} \mathrm{COOH}$.

Table 1

Influence of the solvent on the initial rate and selectivity. Run conditions: $T 358 \mathrm{~K}_{,} \mathrm{CF}_{3} \mathrm{COOH} 1 \mathrm{~mol} \mathrm{~L}-1$, reaction volume $10 \mathrm{~mL}$.

\begin{tabular}{|c|c|c|c|c|c|c|}
\hline Entry & Solvent & $\varepsilon^{\mathrm{a}}$ & $\operatorname{COX}\left(\mathrm{mol} \mathrm{L}^{-1}\right)$ & $r_{0}\left(\times 10^{-5} \mathrm{~mol} \mathrm{~L}^{-1} \mathrm{~s}^{-1}\right)$ & CPL selectivity at complete conversion (\%) & $\mathrm{H}_{2} \mathrm{O}\left(\mathrm{mol} \mathrm{L}^{-1}\right)$ \\
\hline 1 & Toluene & 2.30 & 0.29 & 1.9 & 91 & 0.0002 \\
\hline 2 & 1,2-Dicloroethane & 10.20 & 0.29 & 2.8 & 91 & 0.0002 \\
\hline 3 & $0.43 \mathrm{ACN} / 0.57$ toluene & $10.31^{\mathrm{b}}$ & 0.29 & 3.1 & 88 & 0.001 \\
\hline 4 & $0.55 \mathrm{ACN} / 0.45$ 1,2-dicloroethane & $20.76^{\mathrm{b}}$ & 0.29 & 4.6 & 87 & 0.001 \\
\hline 5 & Benzonitrile & 25.20 & 0.29 & 4.7 & 84 & 0.008 \\
\hline 6 & Nitromethane & 35.87 & 0.29 & 6.1 & 90 & 0.022 \\
\hline 7 & $\mathrm{ACN}$ & 37.50 & 0.29 & 6.0 & 87 & 0.027 \\
\hline 8 & ACN & 37.50 & 0.20 & 4.0 & 89 & 0.027 \\
\hline 9 & $\mathrm{ACN}+\mathrm{H}_{2} \mathrm{O}^{\mathrm{C}}$ & 37.6 & 0.20 & 1.2 & 85 & 0.20 \\
\hline 10 & $\mathrm{ACN}+\mathrm{DMSO}^{\mathrm{d}}$ & 37.6 & 0.20 & 2.3 & 80 & 0.03 \\
\hline 11 & DMF & 37.0 & 0.20 & 0.9 & 10 & 0.03 \\
\hline 12 & DMSO & 46.68 & 0.20 & 0.2 & 0 & 0.03 \\
\hline
\end{tabular}

$\mathrm{COX}=$ cyclohexanone oxime and $\mathrm{CPL}=\varepsilon$-caprolactam.

a Data from [24].

b Calculated following the procedure of [26].

c $\mathrm{H}_{2} \mathrm{O} /$ cyclohexanone oxime $=1 / 1$.

d DMSO/cyclohexanone oxime $=1 / 1$.

the inhibiting effect of the DMSO on the rearrangement. The selectivity to $\varepsilon$-caprolactam decreases, too, this is the effect of the lack in the mass balance, but it is not clear if such a phenomenon is due to $\varepsilon$-caprolactam oligomerization or to cyclohexanone oxime hydrolysis and its further condensation.

The effect of the water on the reaction profile is reported in Fig. 5, there are significant differences with those of, both neat $\mathrm{ACN}$ and $\mathrm{ACN}+\mathrm{DMSO}$, for the presence of a clear induction time of $45 \mathrm{~min}$, in addition, the trifluoroacetyl intermediates are not detected at all. Fig. 6 shows the influence of the water concentration on the $\varepsilon$ caprolactam selectivity and on the reaction rate. Differently of what

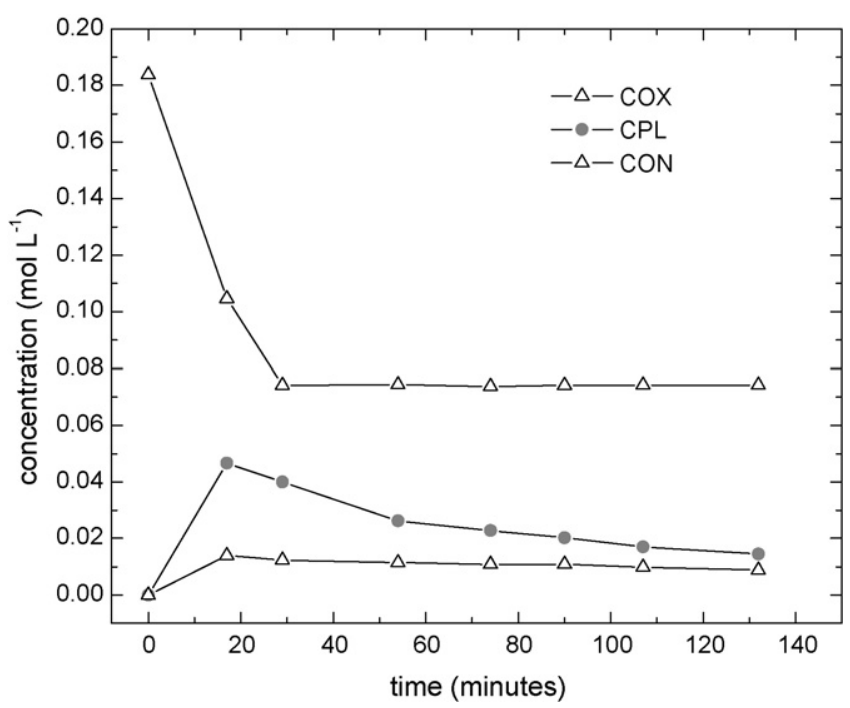

Fig. 2. Concentration time profile in DMF as a solvent. Run conditions: $T 358 \mathrm{~K}$, $\mathrm{COX} 0.19 \mathrm{~mol} \mathrm{~L}^{-1}, \mathrm{CF}_{3} \mathrm{COOH} 1.0 \mathrm{~mol} \mathrm{~L}^{-1}$, reaction volume $10 \mathrm{~mL}$. COX = cyclohexanone oxime, $\mathrm{CPL}=\varepsilon$-caprolactam, $\mathrm{CON}=$ cyclohexanone. expected selectivity towards cyclohexanone does not increase significantly suggesting a non-competitive role of the cyclohexanone oxime hydrolysis on the reaction rate. The behavior of the cyclohexanone oxime hydrolysis, which is poorly influenced by water concentration, suggests also that alternative reaction path involving cyclohexanone oxime self-attack to highly reactive intermediate, as already suggested in a previous paper, may be plausible [13].

As can be observed in Fig. 7 the influence of the solvent on the apparent activation energy is negligible, whose variation from 94 to $102 \mathrm{~kJ} \mathrm{~mol}^{-1}$, for several solvents in a large range of polarity

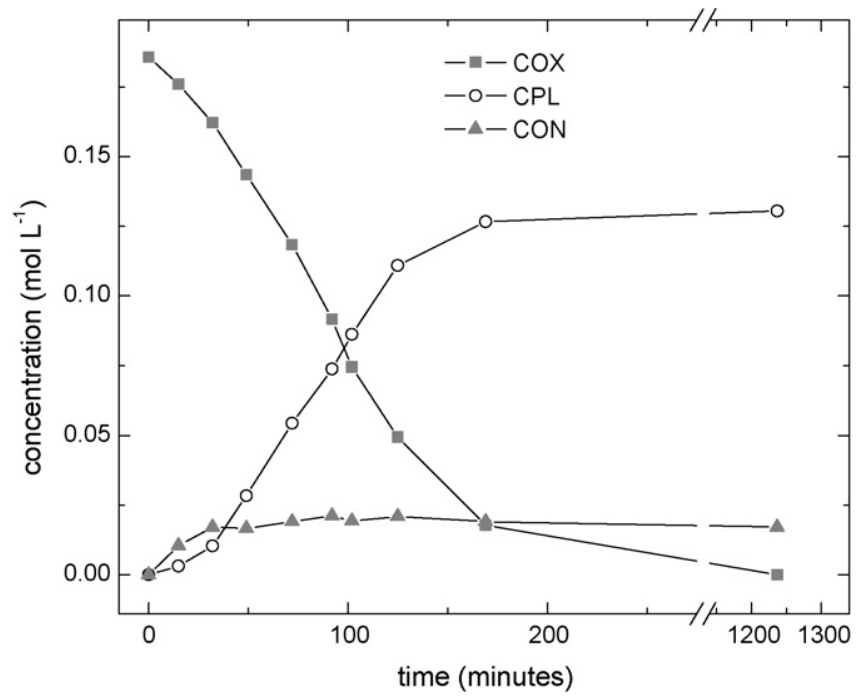

Fig. 3. Concentration time profile in $\mathrm{ACN}$ as a solvent in the presence of DMSO Run conditions: $T 358 \mathrm{~K}$, cyclohexanone oxime $0.20 \mathrm{~mol} \mathrm{~L}^{-1}, \mathrm{CF}_{3} \mathrm{COOH} 1.0 \mathrm{~mol} \mathrm{~L}^{-1}$, DMSO $0.2 \mathrm{~mol} \mathrm{~L}^{-1}$, reaction volume $10 \mathrm{~mL}$. COX $=$ cyclohexanone oxime, $\mathrm{CPL}=\varepsilon-$ caprolactam, $\mathrm{CON}=$ cyclohexanone. 


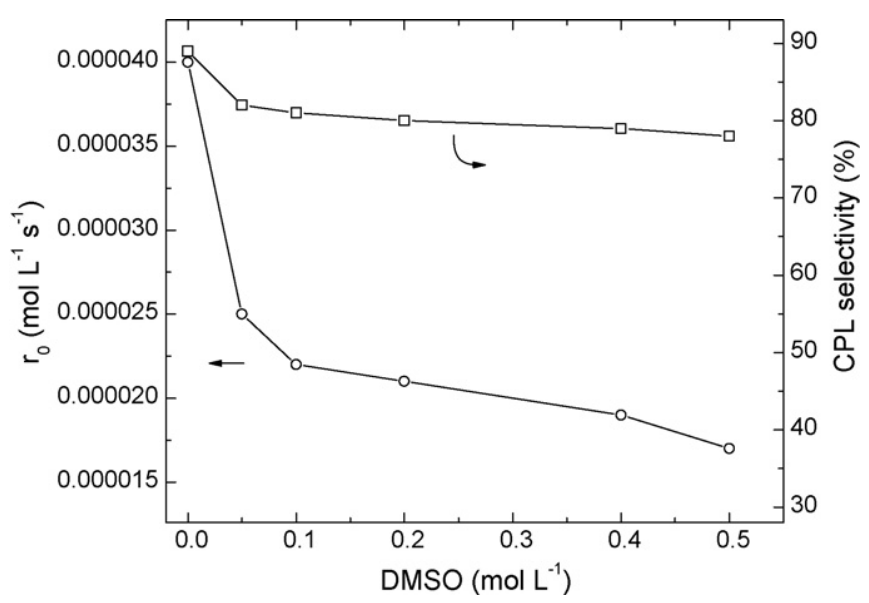

Fig. 4. Influence of DMSO concentration on the initial reaction rate and $\varepsilon$ caprolactam selectivity. Run conditions: $T 358 \mathrm{~K}$, cyclohexanone oxime, $0.2 \mathrm{~mol} \mathrm{~L}^{-1}$ $\mathrm{CF}_{3} \mathrm{COOH} 1 \mathrm{~mol} \mathrm{~L}^{-1}$, solvent $\mathrm{ACN}$, reaction volume $10 \mathrm{~mL}$.

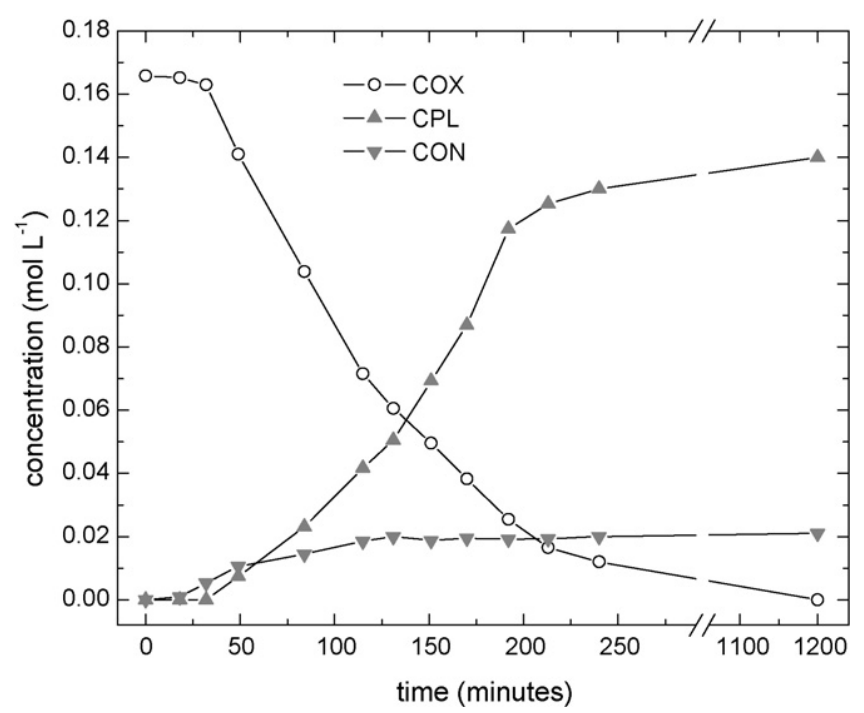

Fig. 5. Concentration time profile in $\mathrm{ACN}$ as a solvent in the presence of $\mathrm{H}_{2} \mathrm{O}$. Run conditions: $T 358 \mathrm{~K}$, cyclohexanone oxime $0.17 \mathrm{~mol} \mathrm{~L}^{-1}, \mathrm{CF}_{3} \mathrm{COOH} 1.0 \mathrm{~mol} \mathrm{~L}^{-1}$ $\mathrm{H}_{2} \mathrm{O} 0.2 \mathrm{~mol} \mathrm{~L}^{-1}$, reaction volume $10 \mathrm{~mL}$. COX $=$ cyclohexanone oxime, $\mathrm{CPL}=\varepsilon$ caprolactam, $\mathrm{CON}=$ cyclohexanone.

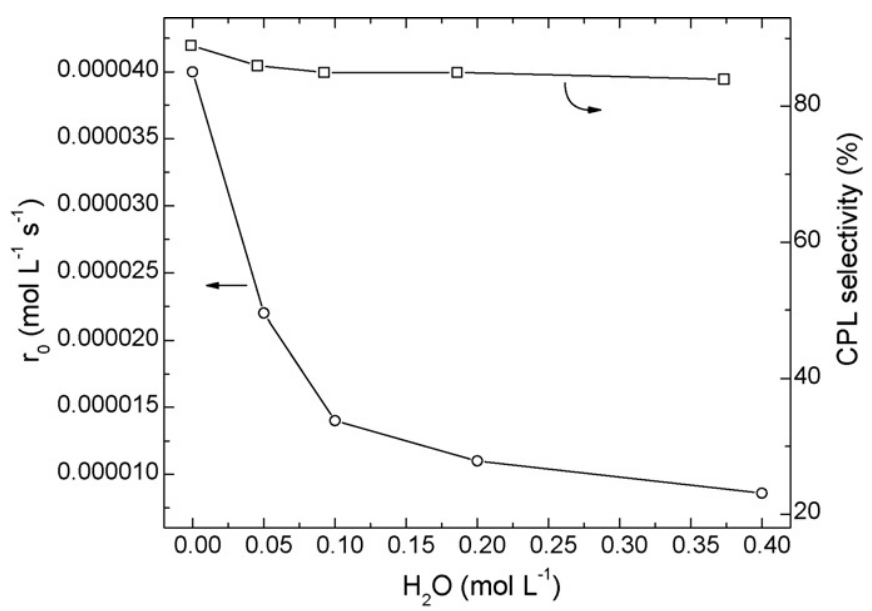

Fig. 6. Influence of $\mathrm{H}_{2} \mathrm{O}$ concentration on the initial reaction rate and $\varepsilon$-caprolactam selectivity. Run conditions: $T 358 \mathrm{~K}$, cyclohexanone oxime $0.2 \mathrm{~mol} \mathrm{~L}^{-1}, \mathrm{CF}_{3} \mathrm{COOH}$ $1 \mathrm{~mol} \mathrm{~L}^{-1}$, solvent $\mathrm{ACN}$, reaction volume $10 \mathrm{~mL}$.

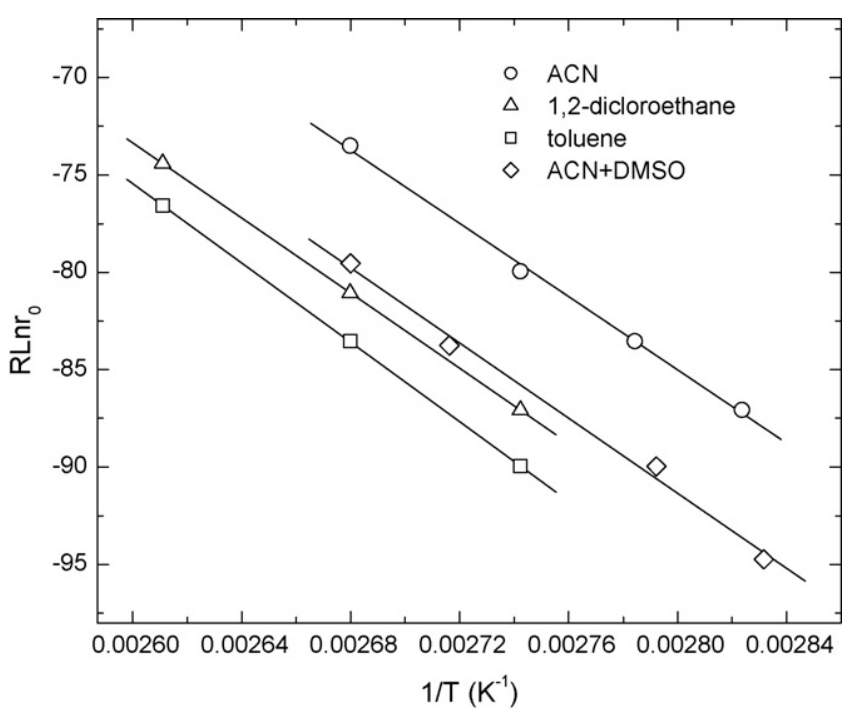

Fig. 7. Apparent activation energy in different solvents: ACN $94 \mathrm{~kJ} \mathrm{~mol}^{-1}, 1,2$ dicloroetano $96 \mathrm{~kJ} \mathrm{~mol}^{-1}$, toluene $102 \mathrm{~kJ} \mathrm{~mol}^{-1}, A C N+$ DMSO $98 \mathrm{~kJ} \mathrm{~mol}^{-1}$. Run conditions: cyclohexanone oxime $0.29 \mathrm{~mol} \mathrm{~L}^{-1}, \mathrm{CF}_{3} \mathrm{COOH} 1.0 \mathrm{~mol} \mathrm{~L}^{-1}$, reaction volume $10 \mathrm{~mL}$.<smiles>O=C(F)ON=C1CCCCC1=NOC(F)(F)F</smiles>

Scheme 2. Esterification of cyclohexanone oxime with $\mathrm{CF}_{3} \mathrm{COOH}$.

(dielectric constant from 2.2 to 37.5 ), is practically into the experimental error. Also the presence of DMSO does not significantly affect the apparent activation energy thus suggesting an inhibitory effect related to a solvent effect of the DMSO on the reaction rate [27]. As suggested in a previous paper [18] trifluoroacetyl cyclohexanone and its subsequent rearrangement is the key step of the reaction, for this reason the presence of $\mathrm{H}_{2} \mathrm{O}$ inhibits the reaction by displacing to the left the cyclohexanone oxime/trifluoroacetyl cyclohexanone oxime esterification equilibrium (Scheme 2 ).

A further proof of such a hypothesis is the clear influence of the water on the apparent activation energy (Fig. 8), which increase from 94 to $120 \mathrm{~kJ} \mathrm{~mol}^{-1}$. Differently of what observed for the inhibitory effect of the DMSO in which no substantial variation of the apparent activation energy has been observed, in this case the increase of $26 \mathrm{~kJ} \mathrm{~mol}^{-1}$ should be accounted for a strong influence of the water on the esterification equilibrium of the cyclohexanone oxime.

A further important behavior is the increasing of the selectivity as the temperature raises (Table 2). Such an effect is probably

Table 2

Influence of the temperature on the initial rate and selectivity. Run conditions: cyclohexanone oxime $0.2 \mathrm{~mol} \mathrm{~L}^{-1}, \mathrm{CF}_{3} \mathrm{COOH} 1 \mathrm{~mol} \mathrm{~L}^{-1}$, ACN as a solvent, reaction volume $10 \mathrm{~mL}$.

\begin{tabular}{lll}
\hline Temperature $(\mathrm{K})$ & $\begin{array}{l}\varepsilon \text {-Caprolactam selectivity at } \\
\text { complete conversion (\%) }\end{array}$ & $r_{0}\left(\times 10^{-5} \mathrm{~mol} \mathrm{~L}^{-1} \mathrm{~s}^{-1}\right)$ \\
\hline 353 & 83 & 2.8 \\
358 & 89 & 4 \\
363 & 92 & 6.7 \\
373 & 95 & 7.5 \\
378 & 95 & 8 \\
\hline
\end{tabular}




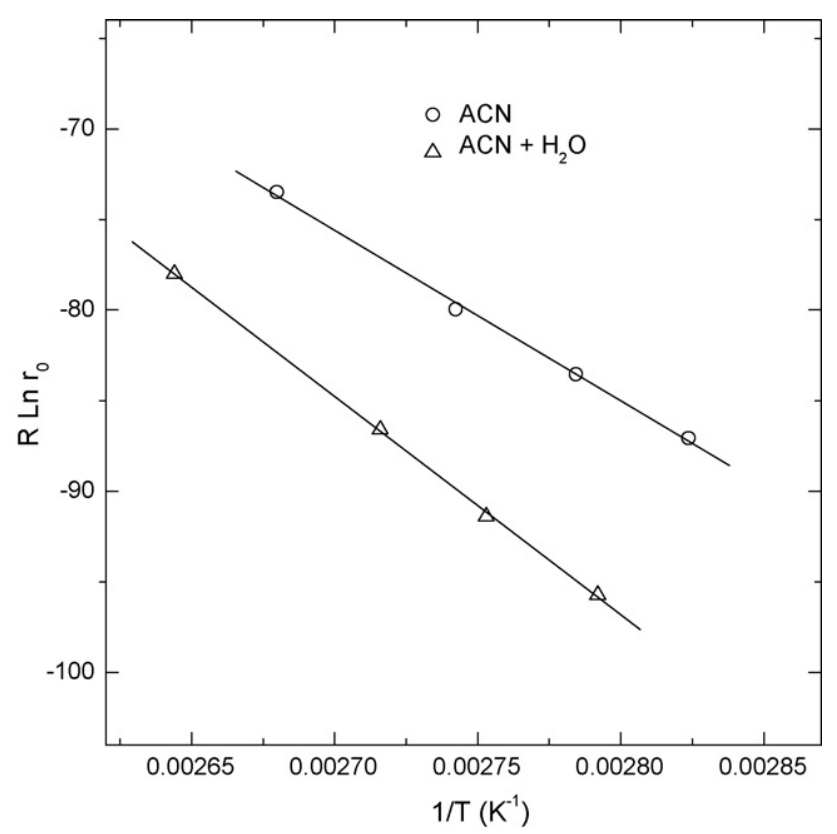

Fig. 8. Comparison of the apparent activation energy in acetonitrile and acetonitrile $+\mathrm{H}_{2} \mathrm{O}$ : acetonitrile $94 \mathrm{~kJ} \mathrm{~mol}^{-1}$, acetonitrile $+\mathrm{H}_{2} \mathrm{O} 120 \mathrm{~kJ} \mathrm{~mol}^{-1}$. Run conditions: cyclohexanone oxime $0.29 \mathrm{~mol} \mathrm{~L}^{-1}, \mathrm{CF}_{3} \mathrm{COOH} 1.0 \mathrm{~mol} \mathrm{~L}^{-1}$, reaction volume $10 \mathrm{~mL}$.

due to the higher value of the apparent activation energy of the rearrangement (ca. $98 \mathrm{~kJ} \mathrm{~mol}^{-1}$ ), compared to that of the cyclohexanone oxime hydrolysis (comprised in the range $21-61 \mathrm{~kJ} \mathrm{~mol}^{-1}$, see later). As a matter of fact, the rate of hydrolysis is favored at low temperatures while at the highest ones the rearrangement is dominant.

\subsection{Influence of the concentration of cyclohexanone oxime, $\mathrm{CF}_{3} \mathrm{COOH}$ and their ratio on reaction rate and selectivity}

The influence of the concentration of the substrate and of the catalyst on reaction rate and selectivity is reported in Figs. 9-11. It appears that on increasing both $\mathrm{CF}_{3} \mathrm{COOH}$ and cyclohexanone oxime concentration, initial reaction rate increases almost linearly (Figs. 9 and 10), also the $\varepsilon$-caprolactam selectivity increases as $\mathrm{CF}_{3} \mathrm{COOH}$ concentration increases, while decreases slightly when the cyclohexanone oxime concentration raises. As expected, the effect of the cyclohexanone oxime concentration on the initial reac-

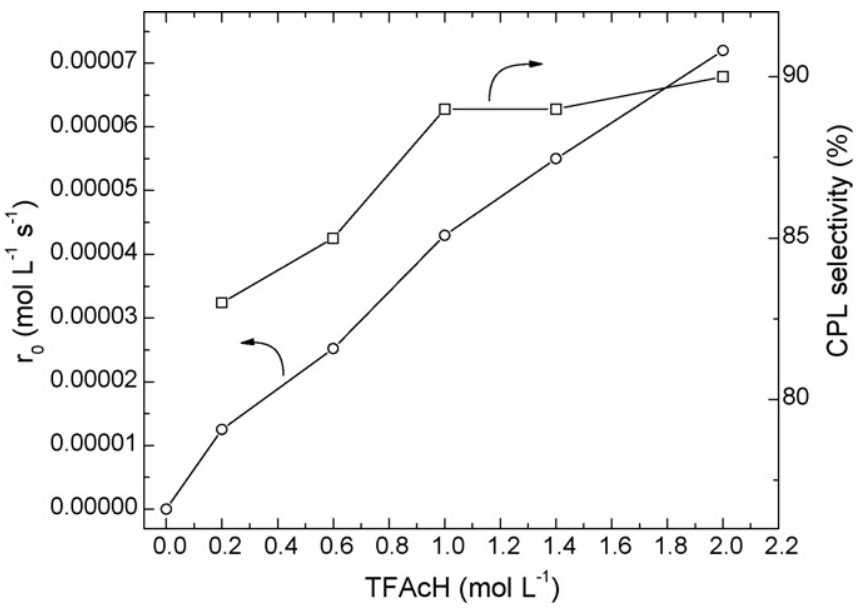

Fig. 9. Influence of the $\mathrm{CF}_{3} \mathrm{COOH}$ concentration on the initial reaction rate and on the $\varepsilon$-caprolactam selectivity. Run conditions: $T 358 \mathrm{~K}$, cyclohexanone oxime $0.2 \mathrm{~mol} \mathrm{~L}^{-1}$, ACN as a solvent, reaction volume $10 \mathrm{~mL}$.

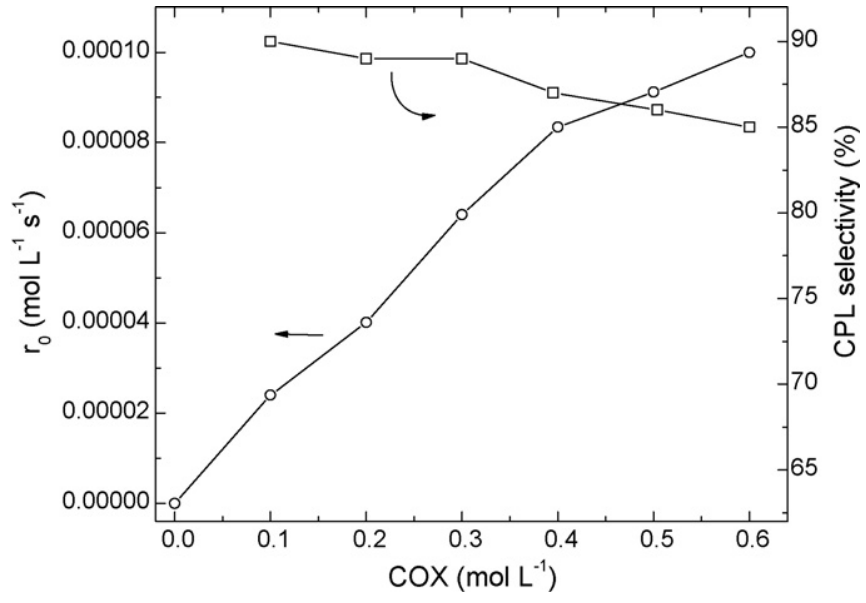

Fig. 10. Influence of the cyclohexanone oxime concentration on the initial reac tion rate and on the $\varepsilon$-caprolactam selectivity. Run conditions: $T 358 \mathrm{~K}, \mathrm{CF}_{3} \mathrm{COOH}$ $1 \mathrm{~mol} \mathrm{~L}^{-1}, \mathrm{ACN}$ as a solvent, reaction volume $10 \mathrm{~mL}$.

tion rate is, proportional to the concentration of the oxime itself at constant [cyclohexanone oxime]/[ $\left.\mathrm{CF}_{3} \mathrm{COOH}\right]$, while selectivity is practically unaffected (Fig. 11). All these evidences corroborate the hypothesis of a strictly dependence of the kinetics from the formation of the trifluoroacetyl cyclohexanone oxime, which, however, does not increases significantly on the time concentration profile as both the concentration of cyclohexanone oxime and $\mathrm{CF}_{3} \mathrm{COOH}$ increase. Such a behavior suggests that the rate limiting step is not a well defined stage and it is likely that both esterification equilibrium and rearrangement of trifluoroacetyl cyclohexanone oxime are determining steps for the kinetics. The stationary state hypothesis is not applicable to esterification equilibrium since kinetic of esterification is not fast enough to be observed at low temperature and equilibrium is achieved only at the temperature when trifluoroacetyl cyclohexanone oxime rearranges, too (see later).

\subsection{Reactivity of the trifluoroacetyl cyclohexanone oxime and the $\mathrm{N}$-trifluoroacetyl caprolactam in acetonitrile}

Similarly to what occur with picriloximes, whose rearrangement occur also without acid catalysis [9,21], also trifluoroacetyl cyclohexanone oxime does and Scheme 3 shows the probable path for catalyzed and uncatalyzed reactions. The time concentration profile of the rearrangement of the trifluoroacetyl cyclohexanone

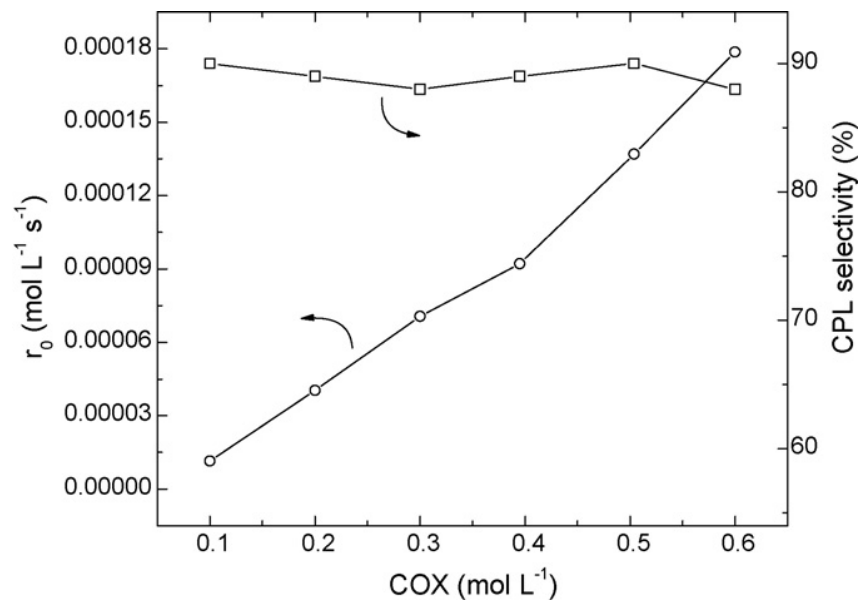

Fig. 11. Influence of the cyclohexanone oxime concentration on the initial reaction rate at $\mathrm{CF}_{3} \mathrm{COOH} /$ cyclohexanone oxime $=5$. Run conditions: $T 358 \mathrm{~K}, \mathrm{ACN}$ as a solvent reaction volume $10 \mathrm{~mL}$. $\mathrm{COX}=$ cyclohexanone oxime, $\mathrm{CPL}=\varepsilon$-caprolactam. 


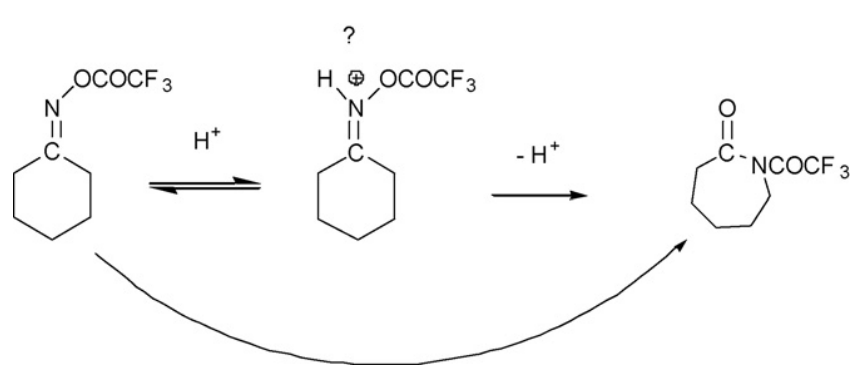

Scheme 3. Rearrangement of trifluoroacetyl cyclohexanone oxime in the presence and without $\mathrm{CF}_{3} \mathrm{COOH}$.

oxime in the presence of $\mathrm{CF}_{3} \mathrm{COOH}$, is reported in Fig. 12. It appears that the $\mathrm{N}$-trifluoroacetyl caprolactam oxime is the main product of the rearrangement but a significant formation of $\varepsilon$-caprolactam (final yield 9\%) is observed. It is likely that such a behavior is due to the presence of $\mathrm{H}_{2} \mathrm{O}$ (the solvent is not dried), which causes the hydrolysis reactions. Fig. 13 shows the time concentration profile of trifluoroacetyl cyclohexanone oxime in acetonitrile without $\mathrm{CF}_{3} \mathrm{COOH}$, the trend is similar to that shown in Fig. 12 and the main differences are the lower initial reaction rate which is 10 times lower $\left(r_{0}=10^{-5} \mathrm{~mol} \mathrm{~L}^{-1} \mathrm{~s}^{-1}\right.$ vs. $\left.r_{0}=10^{-4} \mathrm{~mol} \mathrm{~L}^{-1} \mathrm{~s}^{-1}\right)$ and the higher selectivity in $\varepsilon$-caprolactam compared to that observed in the presence of $\mathrm{CF}_{3} \mathrm{COOH}$ (at complete conversion $9 \%$ and $21 \%$ of yield in $\varepsilon$-caprolactam are observed with and without acid, respectively), thus suggesting a more pronounced hydrolysis of the trifluoroacetyl cyclohexanone oxime in the absence of the acid. In fact, the amount of water present in the solvent ( $c a .0 .05 \%$ $0.027 \mathrm{~mol} \mathrm{~L}^{-1}$ ) is compatible with that of the $\varepsilon$-caprolactam formed. Cyclohexanone is formed in both reactions in trace amount only at the beginning of the reaction suggesting a lower reactivity of the trifluoroacetyl cyclohexanone oxime hydrolysis compared to that of the $\mathrm{N}$-trifluoroacetyl caprolactam (see next section).

These results accord with a dominant $\mathrm{CF}_{3} \mathrm{COOH}$ catalyzed rearrangement of the trifluoroacetyl cyclohexanone oxime. The reason for which protonation of trifluoroacetyl cyclohexanone oxime is not observable, at differences of what found for cyclohexanone oxime [18], is due to the electron withdrawing effect of the trifluoroacetyl group, which strongly diminishes the basicity of the nitrogen.

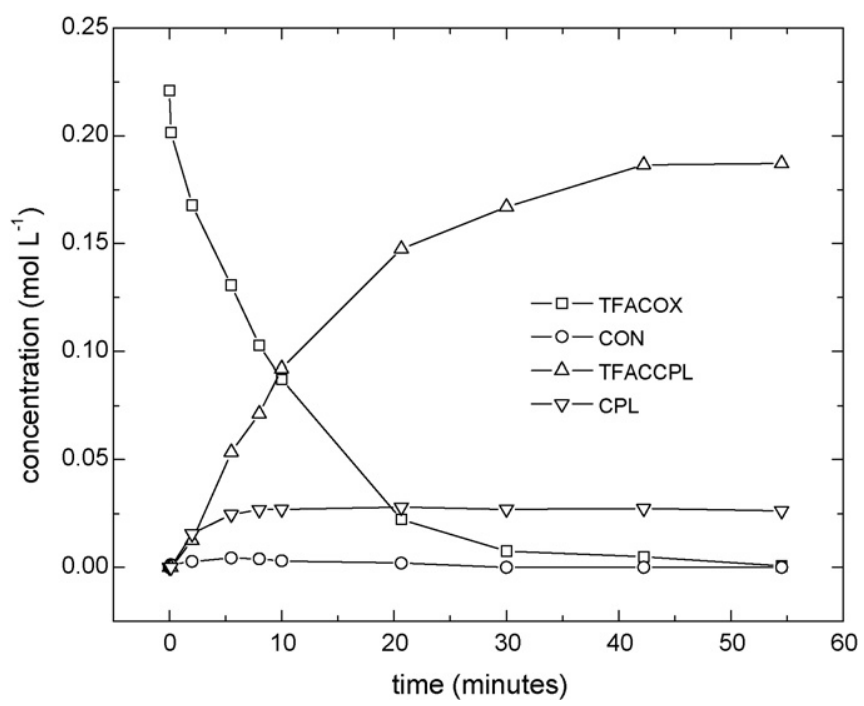

Fig. 12. Concentration time profile of trifluoroacetyl cyclohexanone oxime rearrangement in $\mathrm{ACN}$ as a solvent in the presence of $\mathrm{CF}_{3} \mathrm{COOH}$. Run conditions: $T 358 \mathrm{~K}$ TFACOX $0.22 \mathrm{~mol} \mathrm{~L}^{-1}, \mathrm{CF}_{3} \mathrm{COOH} 1 \mathrm{~mol} \mathrm{~L}^{-1}$, reaction volume $10 \mathrm{~mL}$. Initial reaction rate: $r_{0}=10^{-4} \mathrm{~mol} \mathrm{~L}^{-1} \mathrm{~s}^{-1}$. CON $=$ cyclohexanone, TFACOX $=$ trifluoroacetyl cyclohexanone oxime, $\mathrm{TFACPL}=\mathrm{N}$-trifluoroacetyl caprolactam, $\mathrm{CPL}=\varepsilon$-caprolactam.

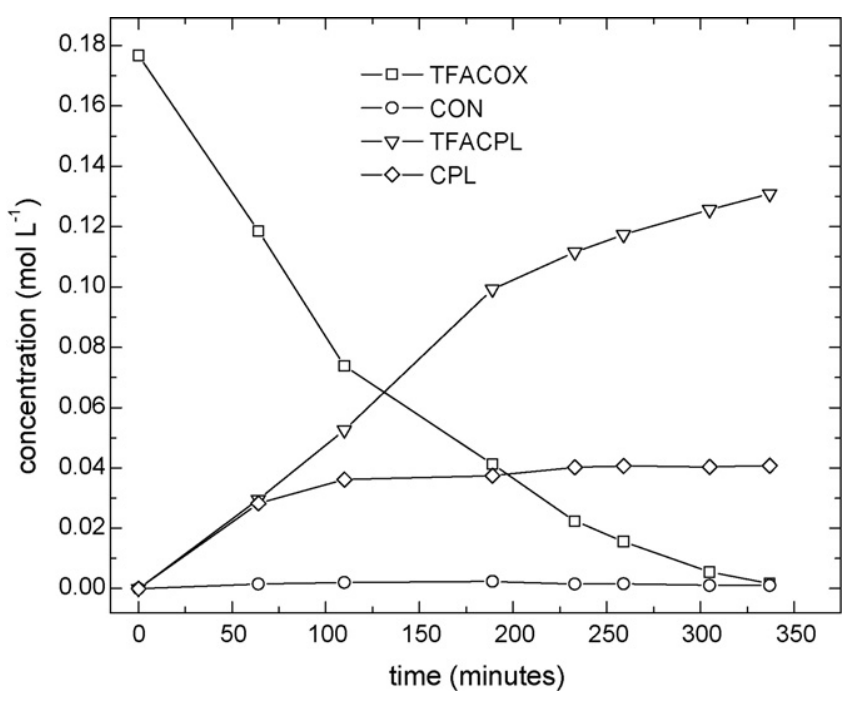

Fig. 13. Concentration time profile of trifluoroacetyl cyclohexanone oxime rearrangement in $\mathrm{ACN}$ as a solvent in the absence of $\mathrm{CF}_{3} \mathrm{COOH}$. Run conditions: $T 358 \mathrm{~K}$ trifluoroacetyl cyclohexanone oxime $0.18 \mathrm{~mol} \mathrm{~L}^{-1}$, reaction volume $10 \mathrm{~mL}$. Initial reaction rate: $r_{0}=10^{-5} \mathrm{~mol} \mathrm{~L}^{-1} \mathrm{~s}^{-1}$. CON $=$ cyclohexanone, TFACOX $=$ trifluoroacetyl cyclohexanone oxime, TFACPL $=\mathrm{N}$-trifluoroacetyl caprolactam $\mathrm{CPL}=\varepsilon$-caprolactam.

As a matter of fact, $\varepsilon$-caprolactam as well as $\mathrm{N}$-trifluoroacetyl caprolactam are not protonated in observable extent (by NMR measurements) under the reaction conditions. This is a result of great importance for a practical development of the process, since a simple distillation allows the recover of both the solvent and the acid without any neutralization.

\subsection{Competitive rearrangements and hydrolysis reactions}

The rate of the rearrangement is compared to the rate of hydrolysis of the cyclohexanone oxime, of the trifluoroacetyl cyclohexanone oxime and of the $\mathrm{N}$-trifluoroacetyl caprolactam. In Table 3 initial rate of reaction without $\mathrm{CF}_{3} \mathrm{COOH}$ and the selectivities towards the main products are reported. As expected cyclohexanone oxime, in the absence of acid catalyst, is quite stable and its rate of hydrolysis is 2 or 3 order of magnitude lower than those of trifluoroacetyl cyclohexanone oxime and N-trifluoroacetyl caprolactam. Time concentration profile of the trifluoroacetyl cyclohexanone oxime hydrolysis shows an almost linear trend of trifluoroacetyl cyclohexanone oxime consumption and cyclohexanone oxime formation together with a practically equimolar formation of $\varepsilon$-caprolactam and cyclohexanone (Fig. 14). It is noteworthy that the rearrangement of trifluoroacetyl cyclohexanone oxime occurs also without acid but in the presence of large amount of water, which gives the hydrolysis of the trifluoroacetyl cyclohexanone oxime to cyclohexanone oxime and $\mathrm{CF}_{3} \mathrm{COOH}$, thus allowing the rearrangement of trifluoroacetyl cyclohexanone oxime also at $298 \mathrm{~K}$. As expected, hydrolysis of $\mathrm{N}$-trifluoroacetyl caprolactam gives quantitatively $\varepsilon$-caprolactam with an initial rate 5 times higher than that of the trifluoroacetyl cyclohexanone oxime (Fig. 15 Table 3). N-trifluoroacetyl caprolactam reacts with cyclohexanone oxime to give trifluoroacetyl cyclohexanone oxime and $\varepsilon$-caprolactam in quantitative yields, confirming the stronger nucleophilic nature of the cyclohexanone oxime with respect to the $\varepsilon$-caprolactam. An attempt to measure the reaction rate of the trifluoroacetyl exchange at $261 \mathrm{~K}$ between $\mathrm{N}$-trifluoroacetyl caprolactam and cyclohexanone oxime does not give reliable results due to the fastness of the reaction (quantitative conversion after a minute both in the absence and in the presence of $\mathrm{CF}_{3} \mathrm{COOH}$ ).

A comparative analysis of the rearrangement and of the hydrolysis of the cyclohexanone oxime is carried out in the presence of 
Table 3

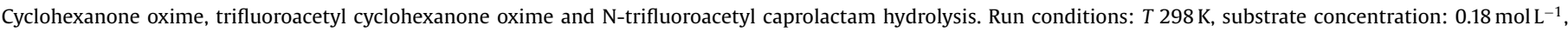
reaction volume: $10 \mathrm{ml}$, substrate $/ \mathrm{H}_{2} \mathrm{O}=1 / 5$

\begin{tabular}{|c|c|c|c|c|c|}
\hline & $r_{0}\left(\times 10^{-5} \mathrm{~mol} \mathrm{~L}^{-1} \mathrm{~s}^{-1}\right)$ & COX selectivity (\%) & CON selectivity (\%) & CPL selectivity (\%) & TFACPL selectivity (\%) \\
\hline COX & $0.01^{\mathrm{a}}$ & 96 & 4 & 0 & 0 \\
\hline TFACOX & 1.8 & 75 & 12 & 12 & 0 \\
\hline TFACPL & 8.7 & 0 & 0 & 100 & 0 \\
\hline
\end{tabular}

$\mathrm{COX}=$ cyclohexanone oxime, $\mathrm{CON}=$ cyclohexanone, $\mathrm{CPL}=\varepsilon$-caprolactam, TFACPL $=$ trifluoroacetyl caprolactam.

a After $20 \mathrm{~h}$ average rate of reaction.

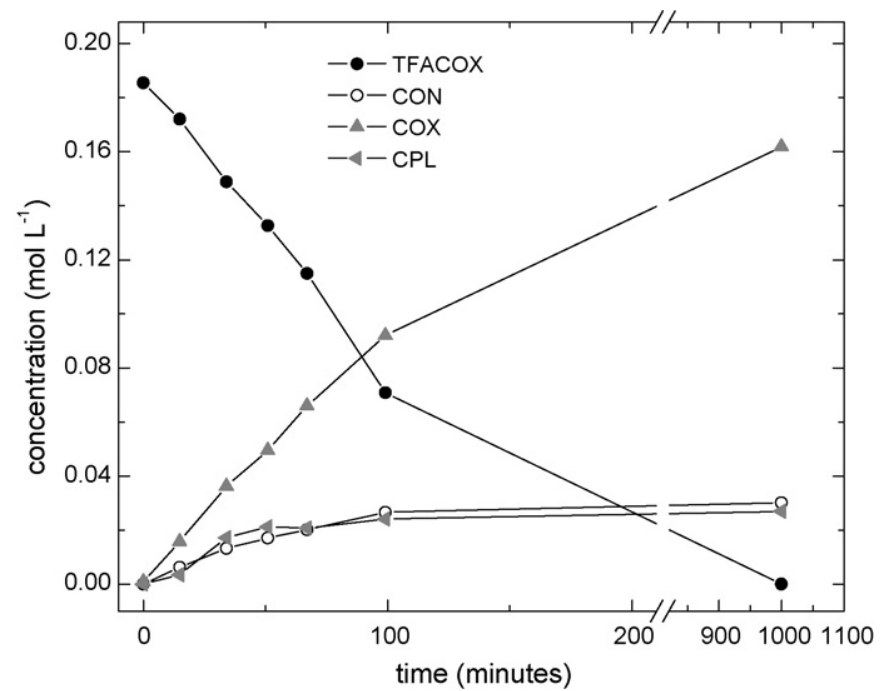

Fig. 14. Concentration time profile of trifluoroacetyl cyclohexanone oxime hydrolysis in ACN. Run conditions: $T 298 \mathrm{~K}$, trifluoroacetyl cyclohexanone oxime $0.19 \mathrm{~mol} \mathrm{~L}^{-1}, \mathrm{H}_{2} \mathrm{O} 1 \mathrm{~mol} \mathrm{~L}^{-1}$, reaction volume $10 \mathrm{~mL}$.

$\mathrm{CF}_{3} \mathrm{COOH}$ at $0.1 \mathrm{~mol} \mathrm{~L}^{-1}$ (10 time lower than the usual concentration) at different temperatures in order to study the selectivity in both $\varepsilon$-caprolactam and cyclohexanone and the trend of initial reaction rate. Two typical time concentration profiles are reported in Figs. 16 and 17. At $378 \mathrm{~K}$ (Fig. 16) after 60 min of induction time rearrangement occurs while at $333 \mathrm{~K}$ (Fig. 17) only the hydrolysis of the cyclohexanone oxime is observed.

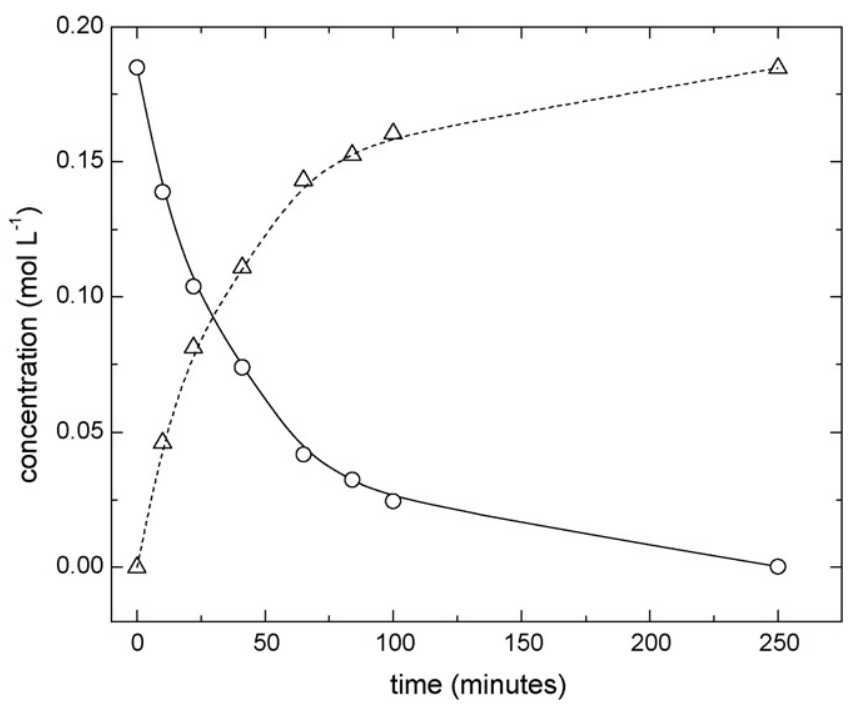

Fig. 15. Concentration time profile of N-trifluoroacetyl caprolactam hydrolysis in ACN. Run conditions: T $298 \mathrm{~K}, \mathrm{~N}$-trifluoroacetyl caprolactam $0.19 \mathrm{~mol} \mathrm{~L}^{-1}, \mathrm{H}_{2} \mathrm{O}$ $1 \mathrm{~mol} \mathrm{~L}^{-1}$, reaction volume $10 \mathrm{~mL}$.

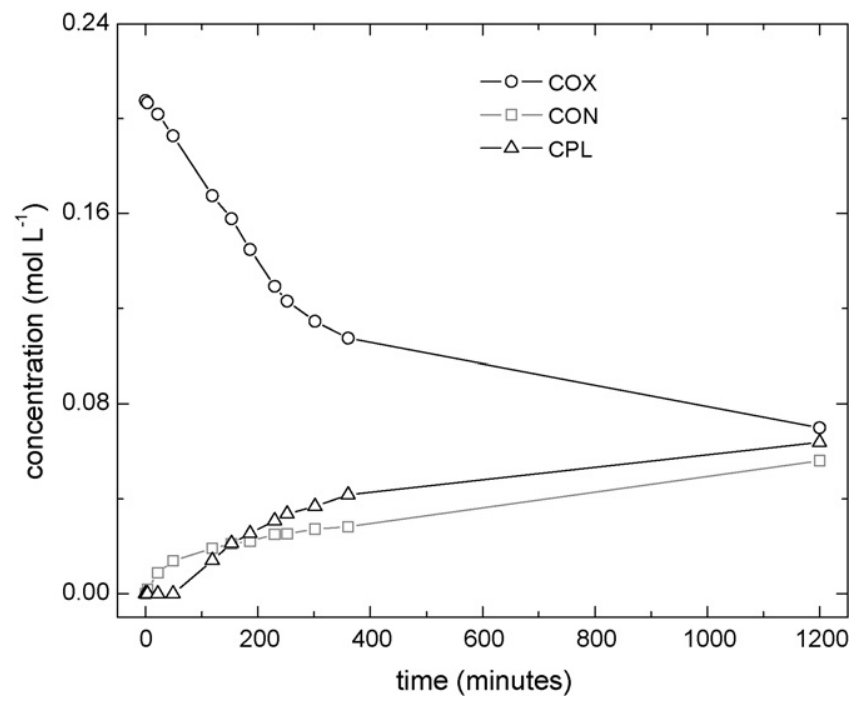

Fig. 16. Concentration time profile of cyclohexanone oxime hydrolysisrearrangement in ACN. Run conditions: $T 378 \mathrm{~K}$, cyclohexanone oxime $0.21 \mathrm{~mol} \mathrm{~L}^{-1}$, $\mathrm{CF}_{3} \mathrm{COOH} 0.1 \mathrm{~mol} \mathrm{~L}^{-1}, \mathrm{H}_{2} \mathrm{O} 1 \mathrm{~mol} \mathrm{~L}^{-1}$, reaction volume $10 \mathrm{~mL}$.

Such an observation is in perfect agreement with the apparent activation energies measured in a large temperature range and reported in Fig. 18, in which can be clearly observed two different slopes: one at high temperature, with an apparent activation energy of $61 \mathrm{~kJ} \mathrm{~mol}^{-1}$ and one at low temperature, with a very small value of $25 \mathrm{~kJ} \mathrm{~mol}^{-1}$. These results explain the reasons of the increasing of the selectivity in $\varepsilon$-caprolactam as the temperature raises. The increase of the activation energy at the higher temperature

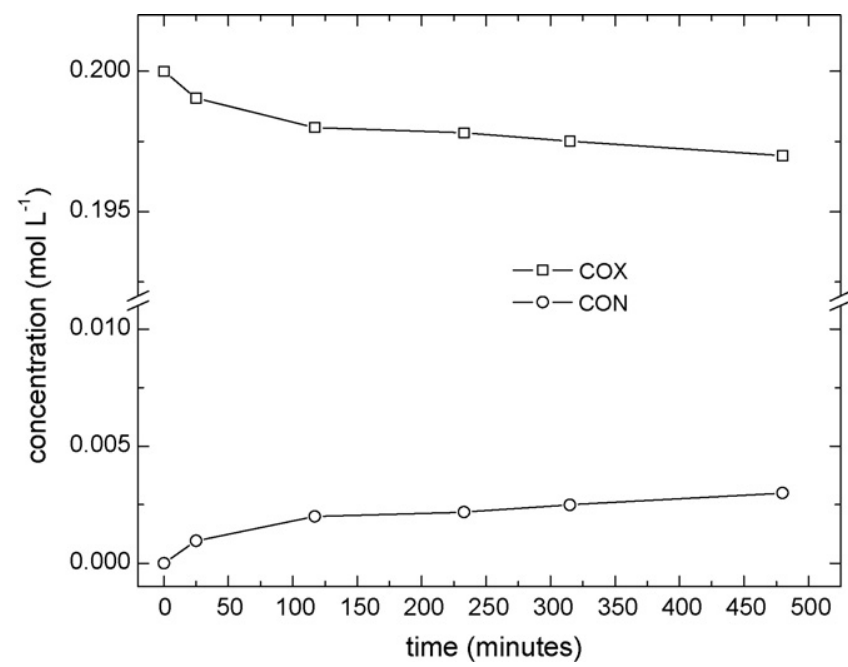

Fig. 17. Concentration time profile of cyclohexanone oxime hydrolysis in ACN. Run conditions: $T 333 \mathrm{~K}$, cyclohexanone oxime $0.20 \mathrm{~mol} \mathrm{~L}^{-1}, \mathrm{CF}_{3} \mathrm{COOH}$ $0.1 \mathrm{~mol} \mathrm{~L}^{-1}, \mathrm{H}_{2} \mathrm{O} 1 \mathrm{~mol} \mathrm{~L}^{-1}$, reaction volume $10 \mathrm{~mL}$. COX = cyclohexanone oxime $\mathrm{CON}=$ cyclohexanone. 


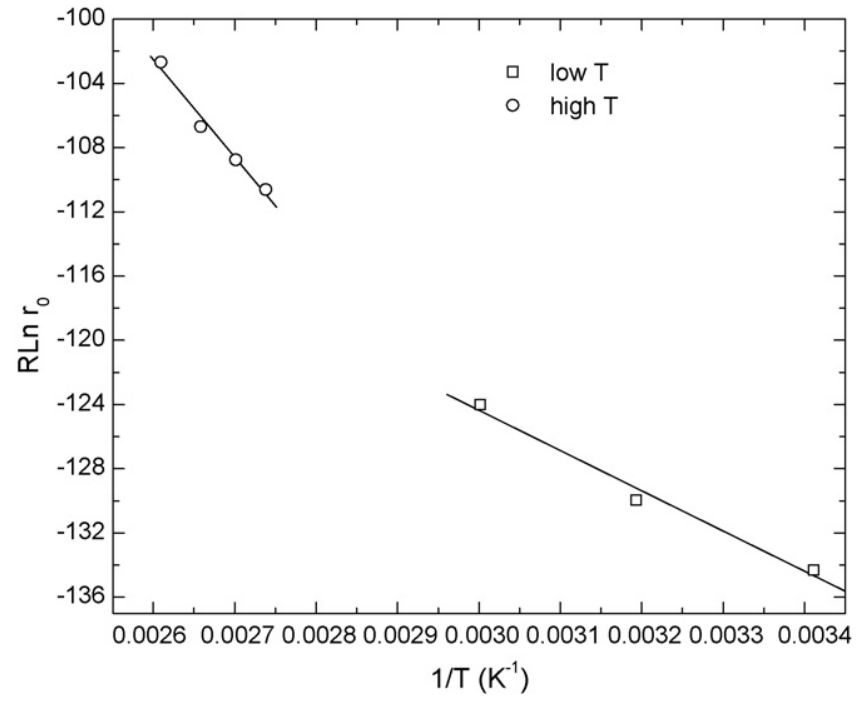

Fig. 18. Variation of the apparent activation energy of cyclohexanone oxime hydrolysis-rearrangement between 295 and $383 \mathrm{~K}$. Run conditions: cyclohexanone oxime $0.19 \mathrm{~mol} \mathrm{~L}^{-1}, \mathrm{CF}_{3} \mathrm{COOH} 0.1 \mathrm{~mol} \mathrm{~L}^{-1}, \mathrm{H}_{2} \mathrm{O} 1 \mathrm{~mol} \mathrm{~L}^{-1}$, reaction volume $10 \mathrm{~mL}$.

is due to the parallel cyclohexanone oxime rearrangement, which extensively occurs. On the contrary, at the lower temperatures the apparent activation energy is due to solely the hydrolysis reaction. The explanation of a so low value of apparent activation energy is not easy, but protonation, formation of charged species and ionic couples may explain a catalytic path whose overall apparent activation energy can be quite low [28]. This matter however, can be object of several conjectures but the real nature of these processes remains totally obscure.

\subsection{On the mechanism of the Beckmann rearrangement in acetonitrile catalyzed by $\mathrm{CF}_{3} \mathrm{COOH}$}

Scheme 4 shows the proposed catalytic cycle of the organocatalyzed Beckmann rearrangement of the cyclohexanone oxime, alternative reaction path and side reactions are omitted for clarity [13]. The catalytic cycle is based essentially on the formation of the trifluoroacetyl cyclohexanone oxime as active catalytic species. The hypothesis of the trifluoroacetyl cyclohexanone oxime protonation, which is not verified by spectroscopic evidences, it is likely because of the higher reactivity of the trifluoroacetyl cyclohexanone oxime in the presence of $\mathrm{CF}_{3} \mathrm{COOH}$ that strongly suggests the involvement of the protonated specie in the reaction mechanism. The nucleophilic attack of the cyclohexanone oxime toward the N-trifluoroacetyl caprolactam is fast and also at $261 \mathrm{~K}$ the reaction is practically at completeness after a minute giving trifluoroacetyl cyclohexanone oxime (the catalytic species) and $\varepsilon$ caprolactam. Likewise, the water acts as nucleophile towards the $\mathrm{N}$-trifluoroacetyl caprolactam giving $\varepsilon$-caprolactam and $\mathrm{CF}_{3} \mathrm{COOH}$. Also in this case the catalytic cycle start again but before the esterification stage, for this reason the overall reaction rate diminishes. In

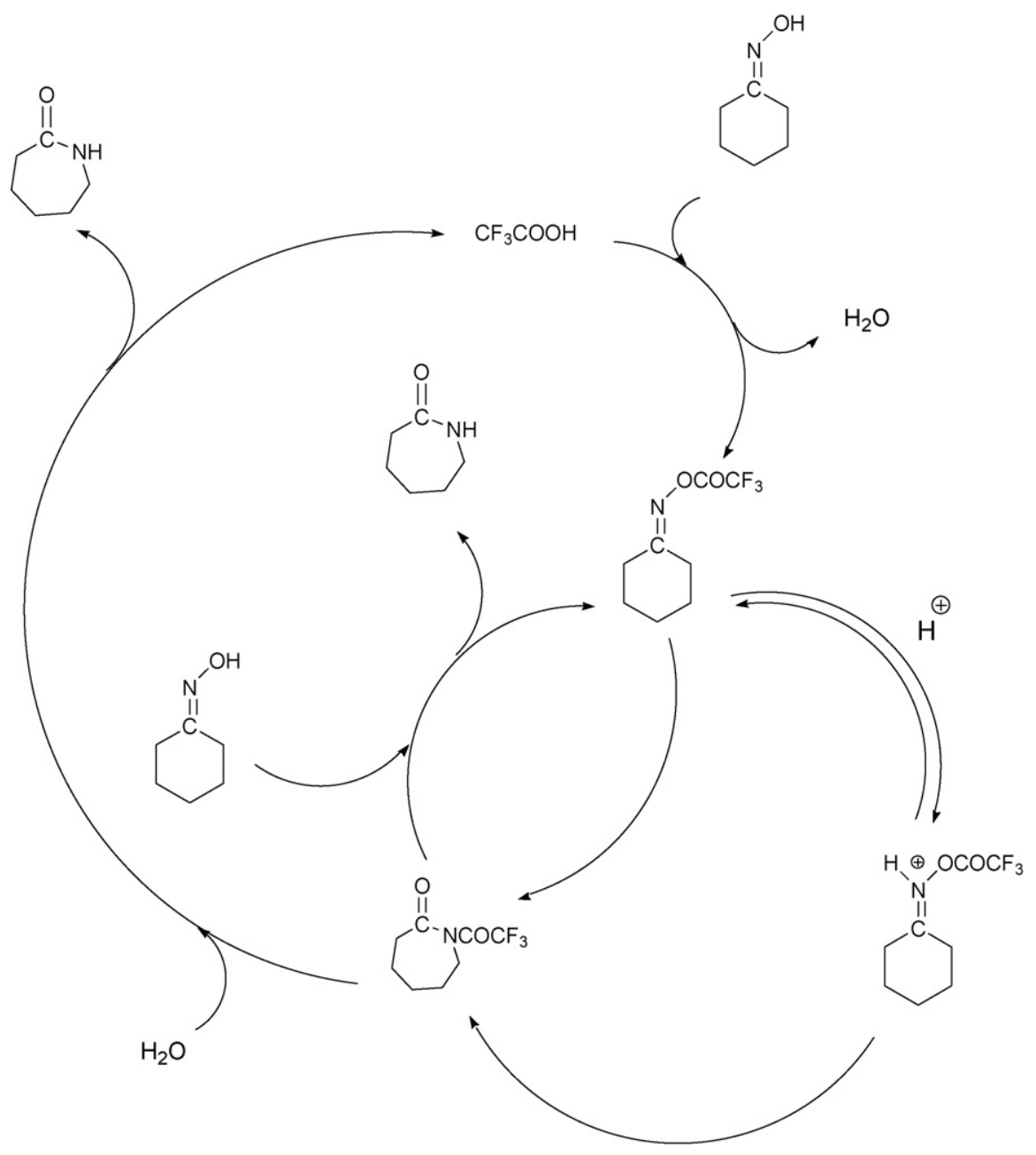

Scheme 4. Catalytic cycle. 
addition, water displaces to the left the esterification equilibrium which causes the weakening of the concentration of the catalytic active trifluoroacetyl cyclohexanone oxime thus lowering the overall reaction rate.

The determination of the rate determining step is not easy, even though the apparent activation energy are quite similar of those catalyzed by mineral acids thus suggesting the rearrangement stage as the slowest one [29], but influence on the overall kinetics of the rate of the esterification step cannot be easily neglected since there are no proofs that this stage is in stationary state. In any case, trifluoroacetyl cyclohexanone oxime is observed in low concentration into the reaction mixture suggesting comparable rate for both processes. The attempt of measuring esterification equilibrium of trifluoroacetyl cyclohexanone oxime is not successful since at low temperature $(261 \mathrm{~K})$ the esterification does not occur and in any case, increasing the temperature in the presence of $\mathrm{CF}_{3} \mathrm{COOH}$, the formation of trifluoroacetyl cyclohexanone oxime is always accompanied with those of $\mathrm{N}$-trifluoroacetyl caprolactam and $\varepsilon$-caprolactam.

\section{Conclusions}

In the present paper we present many aspects of the organocatalyzed Beckmann rearrangement of the cyclohexanone oxime by $\mathrm{CF}_{3} \mathrm{COOH}$. The time concentration profile evidences the formation of both trifluoroacetyl cyclohexanone oxime and N-trifluoroacetyl caprolactam the latter only in trace amount as intermediates. A direct dependence of the reagents concentration on initial reaction rate is observed. Selectivity toward $\varepsilon$-caprolactam is poorly influenced by the amount of reagents and only at the low acid and the high cyclohexanone concentration slightly decreases. The formation of trifluoroacetyl cyclohexanone oxime and N-trifluoroacetyl caprolactam as transient species suggests their involvement as active intermediates of the reaction. The poor influence of the solvent on reaction rate suggests that transition state has the same charge of the reagents and only secondary solvation effect is active. Exceptions are DMF and DMSO: the former gives products of $\varepsilon$ caprolactam oligomerization while the latter does not allow the reaction probably due to the entrapping of the reagents on a solvent cage. The rearrangement of trifluoroacetyl cyclohexanone oxime occurs both in the absence and in the presence of acid, but in the latter case the reaction is 10 times faster. N-trifluoroacetyl caprolactam reacts with cyclohexanone oxime giving trifluoroacetyl cyclohexanone oxime and $\varepsilon$-caprolactam in quantitative amount also at very low temperature $(261 \mathrm{~K})$. Hydrolysis reaction of the trifluoroacetyl cyclohexanone oxime is accompanied by the rearrangement due to the formation of $\mathrm{CF}_{3} \mathrm{COOH}$, while $\mathrm{N}$ trifluoroacetyl caprolactam gives quantitatively $\mathrm{CPL}_{2}$ and $\mathrm{CF}_{3} \mathrm{COOH}$. The cyclohexanone oxime hydrolysis to cyclohexanone is the main side reaction but is slightly influenced by $\mathrm{H}_{2} \mathrm{O}$ concentration and cyclohexanone selectivity is mainly influenced by reaction temperature. The concentration of cyclohexanone oxime, $\mathrm{CF}_{3} \mathrm{COOH}$ and their ratio are directly related to initial reaction rate suggesting a limiting intermediate or precursor in equilibrium with both cyclohexanone oxime and $\mathrm{CF}_{3} \mathrm{COOH}$. On the basis of these evidences and taking into account the reactivity of the trifluoroacetyl compounds, we suggest an active role as catalytic active specie of trifluoroacetyl cyclohexanone oxime and a promoting effect of the acid itself on the rearrangement of the trifluoroacetyl cyclohexanone oxime even though a non-catalyzed rearrangement of the trifluoroacetyl cyclohexanone oxime is possible. The rate determining step cannot be experimentally recognized because of the presence of the equilibrium stage of oxime esterification, which occurs simultaneously with the rearrangement.

\section{Acknowledgements}

Financial support by Ca' Foscari University of Venice is gratefully acknowledged (Ateneo fund 2008). A special thank to Mr. Claudio Tortato for the helpful discussions. A great thank also to Dr. Marco Bortoluzzi, who carried out NMR measurements and for the profitable discussions and the valuable suggestions.

\section{References}

[1] W.B. Fisher, L. Crescentini, Kirk Othmer Encyclopedia of Chemical Technology, vol. 18, Wiley Interscience, 1982 , p. 874.

[2] G. Petrini, G. Leonfanti, M.A. Mantegazza, F. Pignataro, in: P.T. Anastas, T.C. Wiliamson (Eds.), Green Chemistry Designing Chemistry for the Environment 1998, p. 33.

[3] G. Fisher, Fibres Text. East. Eur. 11 (2003) 14.

[4] S. Van der Linde, G. Fisher, Fibres Text. East. Eur. 12 (2004) 17.

[5] L. Forni, G. Fornasari, F. Trifirò, A. Aloise, A. Katovic, G. Giordano, J.B. Nagy, Micropor. Mesopor. Mater. 101 (2007) 153.

[6] W.F. Holderich, G. Dahloff, H. Ichihashi, K. Sugita, US Patent 6,531,595 B2 (2003); to Sumitomo Chemical Company.

[7] L. De Luca, G. Giacomelli, A. Porcheddu, J. Org. Chem. 67 (2002) 6272.

[8] B. Wang, Y. Gu, C. Luo, T. Yang, L. Yang, J. Suo, Tetrahedron Lett. 45 (2004) 3369.

[9] B. Jones, Chem. Rev. 35 (1944) 335.

[10] A.W. Chapmann, C.C. Howis, J. Chem. Soc. (1933) 806

[11] F.A. Carey, R.J. Sundberg, Advanced Organic Chemistry Part B, 540, third ed., Plenum Press, New York, 1990.

[12] M.T. Nguyen, G. Raspoet, L.G. Vanquickenborne, J. Am. Chem. Soc. 119 (1997) 2552.

[13] L. Ronchin, M. Bortoluzzi, A. Vavasori, J. Mol. Struct.: THEOCHEM 858 (2008) 46.

[14] S. Yamabe, N. Tsuchida, S. Yamazaki, J. Org. Chem. 70 (2005) 10638.

[15] X. Liu, L. Xiao, H. Wua, Z. Li, J. Chen, C. Xia, Catal. Commun. 10 (2009) 424

[16] A. Zicmanis, S. Katkevica, P. Mekss, Catal. Commun. 10 (2009) 614.

[17] N.C. Marziano, L. Ronchin, C. Tortato, A. Vavasori, M. Bortoluzzi, J. Mol. Catal. A: Chem. 290 (2008) 79.

[18] L. Ronchin, A. Vavasori, M. Bortoluzzi, Catal. Commun. 10 (2008) 251.

[19] W.Z. Heldt, J. Org. Chem. 26 (1960) 1695.

[20] S. His, C. Meyer, J. Cossy, G. Emeric, A. Greiner, Tetrahedron Lett. 44 (2003) 8581

[21] J.D. McCullough Jr., D.Y. Curtin, I.C. Paul, J. Am. Chem. Soc. 94 (1972) 874

[22] A.C. Huitric, S.D. Nelson, J. Org. Chem. 34 (1969) 1232.

[23] W.Z. Heldt, J. Am. Chem. Soc. 80 (1958) 5880.

[24] H. Stephen, B. Staskum, J. Chem. Soc. (1956) 980.

[25] C. Reichardt, Solvents and Solvent Effects in Organic Chemistry, second ed., VCH Weinheim, 1988, p. 79

[26] K. Ueda, K. Yamada, M. Nakai, T. Matsuda, M. Hosoda, K. Tai, Polym. J. 28 (1996) 446.

[27] R. Yang, S.G. Schulman, Luminescence 20 (2005) 358

[28] V.N. Parmon, React. Kinet. Catal. Lett. 78 (2003) 139.

[29] N.C. Marziano, C. Tortato, L. Ronchin, O. Tonon, R. Bertani, Int. J. Chem. Kinet. 36 (2004) 417. 